\title{
Prevalence of Metabolic Syndrome in Patients with Diabetes Mellitus Type 2 Attending Tribhuwan University Teaching Hospital
}

\author{
Lilee Shrestha ${ }^{1 *}$, Saroj Sharma ${ }^{2}$, Bharat Jha ${ }^{3}$, Prem Khadga ${ }^{4}$
}

BACKGROUND: Metabolic syndrome (Met S) is a cluster of biochemical and physical conditions that presage the development of atherosclerotic cardiovascular disease. Its association with diabetes mellitus has long been a topic of study. This study intends to find out the prevalence of Met $S$ in Nepalese population using IDF criteria.

METHODS: This cross-sectional study was carried out in department of medicine and department of biochemistry, Tribhuwan University teaching hospital, Maharajgunj, Kathmandu. 204 diabetic subjects, with age ranging between 31 to 80 years and similar number of healthy controls were recruited for study. Demographic, anthopometric and biochemical data were obtained as per preformed profoma. Statistical analysis was done using SPSS statistical software version 17.0.

RESULTS: Prevalence of metabolic syndrome in diabetic population was found to be $67.3 \%$, while it was only $7.84 \%$ in control group. Prevalence was found to be higher in females compared to males.

CONCLUSIONS: Prevalence of metabolic syndrome is significantly higher in diabetic subjects, making them highly prone to the ill effects of cardiovascular diseases.

\section{(C) 2015 Nepalese Association for Clinical Chemistry}

\section{Introduction}

The metabolic syndrome (Met S), also called insulin resistance syndrome or syndrome $\mathrm{X}$, is a cluster of risk factors that is responsible for much of the excess cardiovascular disease morbidity amongst overweight and obese patients and those with Type 2 Diabetes Mellitus (T2DM) [1] Met $\mathrm{S}$ is associated with increased cardiovascular disease leading to increased cardiovascular (CV) morbidity and mortality [2-8] It is also an independent predictor of cerebrovascular events and is also related to an increased risk of all-cause mortality $[3,5,7]$.

Among the various criteria employed for detection of Met $S$, the one put forward by IDF is employed in this study.

IDF criteria for metabolic syndrome: [9]

Central Obesity as defined for Asian population (Waist Circumference $\geq 90 \mathrm{~cm}$ in men, $\geq 80 \mathrm{~cm}$ in women), together with two of the following:

Blood Pressure (Systolic blood pressure $\geq 130$ $\mathrm{mmHg}$, Diastolic BP $\geq 85 \mathrm{mmHg}$ ) or treatment of previously diagnosed hypertension

Fasting Plasma Glucose $\geq 5.6 \mathrm{mmol} / \mathrm{L}$ or previously diagnosed type 2 diabetes

HDL Cholesterol $<1.03 \mathrm{mmol} / \mathrm{L}$ in men, $<1.29$ $\mathrm{mmol} / \mathrm{L}$ in women

Triglycerides $\geq 1.7 \mathrm{mmol} / \mathrm{L}$

In the last decade, Met $S$ has garnered considerable interest due to its strong association with diabetes. Insulin resistance is presumed to play a major role, both in pathogenesis of diabetes mellitus and in the genesis of Met S. Evidence is accumulating that insulin resistance may be the common aetiological factor for the individual components of the Met $S$, although there appears to be heterogeneity in the strength of the insulin resistance relationship with different components between, and even within, populations [2, 10, 11]. Due to this relationship, it comes to us as no surprise that diabetes and Met $S$ are closely associated.

Although the reported prevalence of Met $S$ in general population differs widely among the ethnic groups $[12,13]$ and according to definition of Met $S$ used [4, 14-16] the prevalence among diabetic population is very high, regardless of ethnicity and definition [3, 4, 17-19].

\footnotetext{
1JFIHS, Balaju, Kathmandu. ${ }^{2}$ BTI, Gongabu, Kathmandu. ${ }^{3}$ Department of Biochemistry, Institute of Medicine, Maharajgunj, Kathmandu. ${ }^{4}$ Department of Medicine, Institute of Medicine, Maharajgunj, Kathmandu
} 
It is essential to identify prevalence of Met $S$ in diabetic patients without cardiovascular diseases (CVD) as diabetic patients with Met $S$ have higher incidence of CVD than those without Met $S[6,19]$ and Met $S$ is stronger risk factor for CVD in patients with T2DM than in nondiabetic patients [3]

Thus, this study aims to find prevalence of Met $S$ in patients with T2DM.

\section{Methods}

This was a cross-sectional study conducted at Tribhuvan University Teaching Hospital, Maharajgunj, Kathmandu, from September 2011 to October 2012. The study was ethically approved by Institutional Review Board. Written consent was taken from every participant or visitors of participants, if participants were unable to do so.

A total of 204 subjects (102 males and 102 females), diagnosed with T2DM as defined by expert committee on diagnosis and classification of diabetes mellitus were enrolled in this study.

Participants were interviewed by asking the questions included in questionnaire. Variables as weight, height, waist circumference and blood pressure were measured. Five $\mathrm{mL}$ of blood was drawn after an overnight fast ( $8-12$ hours) by venous puncture. It was then analysed for glucose and lipid profile. Similar procedure was carried out with equal number of age and sex matched control group. Nondiabetic individuals, with no other chronic illness as Chronic kidney disease (CKD), CVD, and apparently healthy were recruited as controls.

IDF criteria were used to identify the subjects with Met S. Statistical analyses were done by SPSS 17.0 version (Statistical Package for Social Science for Window version; SPSS, Inc., Chicago, IL).

\section{Results}

All together 408 subjects were enrolled in this study. Among them, 204 were diabetic individuals and equal number of healthy control was recruited. Among them, 102 were male and 102 were female in the diabetic group and same number of males and females in the control group. Mean age of cases was $54.42 \pm 11.9$ (range: $31-80$ years) and that of control group was 54.43 \pm 11.91 (range: $31-80$ years). The Waist Circumference, Blood pressure (BP), Fasting Blood glucose (FBG), Total Cholesterol (TC), LDL-Cholesterol (LDL-C) and Triacylglycerol (TG) were found significantly higher in cases compared to control (Table 1).

Prevalence of Met $S$ was found to be $63.7 \%$ in case group, while the prevalence of the same in normal control group was $7.84 \%$ (Figure 1).

Gender wise, metabolic syndrome showed comparatively high prevalence in females than in males. The percentage of diabetic females with Met $S$ was $70.9 \%$, while $55.1 \%$ of diabetic males had Met $S$ (Figure 2).

\section{Discussion}

Various studies have demonstrated higher prevalence of Met $S$ in diabetic population compared to normal individuals. Our study also supports this fact. In our study, $63.7 \%$ of case group were shown to have metabolic syndrome while the prevalence of the same in normal control group was $7.84 \%$.

Table 1. Anthropometric and biochemical characteristics of cases and control

\begin{tabular}{lccc}
\hline Parameter & Cases $($ Mean \pm S.D.) & Control $($ Mean \pm S.D.) & p value* \\
\hline Waist Circumference (cms) & $91.33 \pm 9.73$ & $82.73 \pm 4.15$ & $<0.001$ \\
BP (systolic) $\mathrm{mmHg}$ & $122.35 \pm 8.57$ & $116.10 \pm 6.83$ & $<0.001$ \\
BP (Diastolic) $\mathrm{mmHg}$ & $80.40 \pm 6.95$ & $76.08 \pm 5.81$ & $<0.001$ \\
FBG (mmol/L) & $7.38 \pm 2.50$ & $4.6 \pm 0.86$ & $<0.001$ \\
TC $(\mathrm{mmol} / \mathrm{L})$ & $5.15 \pm 1.98$ & $4.20 \pm 0.76$ & $<0.001$ \\
HDL-C (mmol/L) & $0.99 \pm 0.19$ & $1.01 \pm 0.19$ & 0.42 \\
VLDL-C (mmol/L) & $0.98 \pm 0.39$ & 0.79 & 0.14 \\
LDL-C (mmol/L) & $3.1 \pm 1.04$ & $2.57 \pm 0.76$ & $<0.001$ \\
TG $(\mathrm{mmol} / \mathrm{L})$ & $2.16 \pm 0.88$ & $1.35 \pm 0.36$ & $<0.001$ \\
\hline
\end{tabular}

*Student's t-test was applied. 


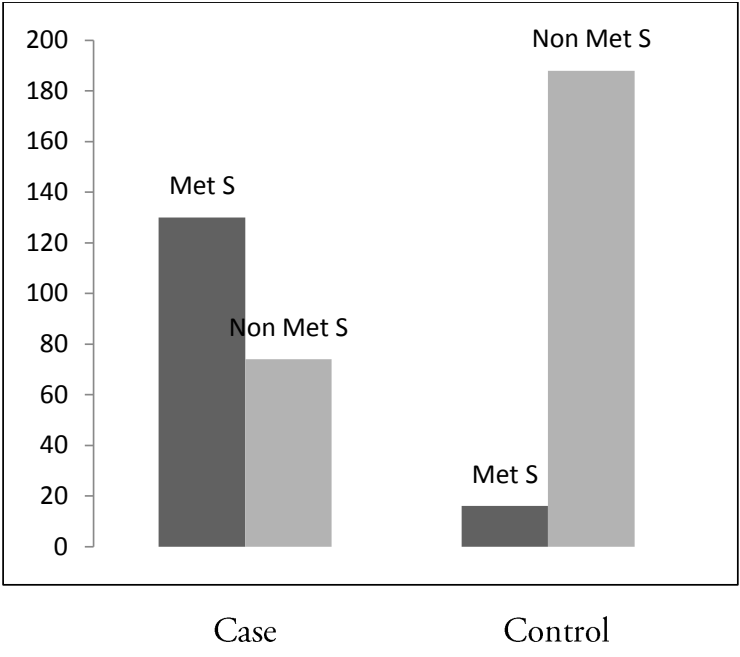

Figure 1. Prevalence of Met $S$ in case and control.

A hospital based cross sectional study conducted in diabetes patients aged between 25-75 years of age presenting to Manipal Teaching Hospital, Pokhara also reported such higher prevalence. However, the prevalence of Met $S$ in diabetic population in that study was comparatively higher than in ours. According to this study, the prevalence of Met $S$ in diabetes patients as per NCEP/ATP III and IDF criteria were 71\% (72\% in males and $91 \%$ in females) and $82 \%(80 \%$ in males and $95 \%$ in females) respectively [20].

Similar kind of study was conducted in Pakistan. Out of the100 participants seventy six (76\%) were diagnosed to have Met $S$. Of the 56 females, forty eight $(85.71 \%)$ were having Met $S$ while twenty eight $(63.63 \%)$ of the 44 male participants were having the syndrome. The difference was statistically significant $(\mathrm{p}<0.05)$ [21]. Another study conducted on a large number of patients (5088; 2908 men and 2180 women) also concluded with similar findings. The prevalence of Met $S$ in diabetic population in this study was found to be $77.2 \%$. $(87.71 \%$ in women and $69.33 \%$ in men). However, NCEP/ATP III criteria were used in this study to diagnose Met $S$ [22].

A study carried out in Korea reported the prevalence of Met $S$ in Korean type 2 diabetic patients to be $62.0 \%$ (53.7\% in men and $68.9 \%$ in women). Total 989 Korean patients (452 men and 537 women, $59 \pm 10$ year of age) with type 2 diabetes were studied. The reported prevalence is moreover similar to that obtained in our study.

However, Met $S$ was defined by NCEP-ATP III criteria or by modified NCEP-ATP III criteria which adopt the definition of abdominal obesity in Asia-Pacific region $(\mathrm{M}:>90 \mathrm{~cm}, \mathrm{~F}:>80 \mathrm{~cm}$ ), in contrast to IDF criteria used in our study [23].

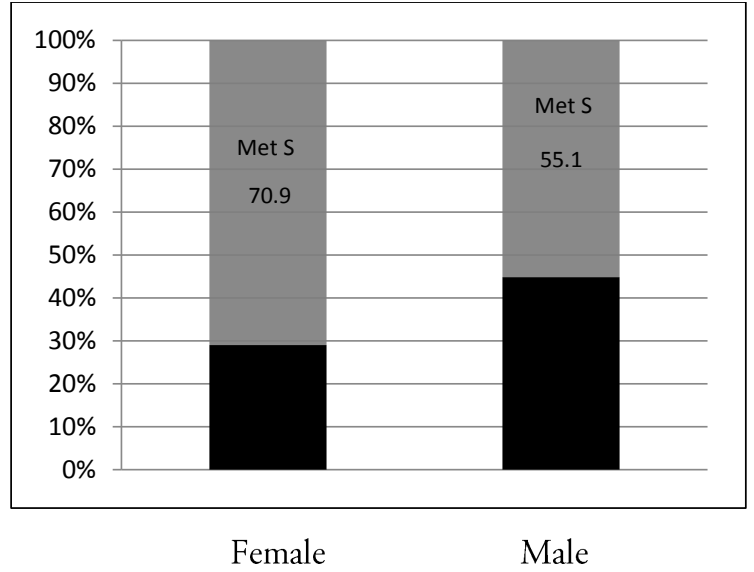

Figure 2. Genderwise prevalence of Met $S$.

Another inference that can be drawn from above studies, besides the high prevalence of Met $S$ in diabetic population, is that gender wise, metabolic syndrome comparatively has high prevalence in female sex than in males. Similar reports are obtained by Kalish et al. [24], Sarrafzadegan et al. [25] and Rizwan et al. [26] Our study provides further support to this finding. In our study $55.1 \%$ of diabetic males had Met-S while $70.9 \%$ of diabetic females had Met $S$.

High prevalence of Met $S$ in female can be related to increase obesity in female and lower level of physical activity and high calories food, and all these factors contributing to insulin resistance and Met $S$. The mechanism by which excessive body fat causes insulin resistance and impairs glucose metabolism is not clearly defined, but fat stores are an important cause of increased free fatty acid and triglyceride in the skeletal muscle, which impairs insulin secretion [27]. This could also partially be attributed to the lower cut-off for waist circumference and higher cut-off for HDL in women as compared to men. Therefore, probably more women were classified as having central obesity or low HDL.

Some other studies reporting higher prevalence of Met $S$ in diabetic individuals are by Imam et al. [28] reporting a prevalence of $79.7 \%$ from Pakistan, Bruno et al. [29] reporting a prevalence of $75.6 \%$ from the USA, Foucan et al. [30] reporting a $77 \%$ prevalence of metabolic syndrome in diabetic Indian immigrants in the USA and Thanaa et al. [27], reporting 66.5\% prevalence from Iraq.

\section{Conclusion}

Prevalence of metabolic syndrome is significantly higher in diabetic subjects, making them highly prone to the ill effects of cardiovascular diseases 
Conflict of Interest: None declared.

1. Vega GL. Obesity, The Metabolic Syndrome and Cardiovascular Disease. Am Heart J, 2001; 142: 1108-1116

2. Zimmet PZ. Kelly West Lecture 1991. Challenges in diabetes epidemiology_from West to the rest. Diabetes Care 1992;15:232- 52.

3. Isomaa $\mathrm{B}$, Almgren $\mathrm{P}$, Tuomi $\mathrm{T}$, Forsen B, Lahti $\mathrm{K}$ et al. Cardiovascular morbidity and mortality associated with the metabolic syndrome. Diabetes Care 2001;24:683-89.

4. Lakka HM, Laaksonen DE, Lakka TA, Niskanen LK, Kumpusalo E et al. The metabolic syndrome and total and cardiovascular disease mortality in middle-aged men. JAMA 2002;288:2709-16.

5. Trevisan $\mathrm{M}$, Liu J, Bahsas FB, Menotti A: Syndrome X and mortality. A population-based study. Risk Factor and Life Expectancy Research Group. Am J Epidemiol 1998;148:958-66.

6. Bonora E, Targher G, Formentini G, Calcaterra F, Lombardi $S$ et al. The metabolic syndrome is an independent predictor of cardiovascular disease in type 2 diabetic subjects: prospective data from the verona diabetes complications study. Diabet Med 2004;21:52-58.

7. Hu G, Qiao Q, Tuomilehto J, Balkau B, Borch-Johnsen K, Pyorala K, DECODE Study Group. Prevalence of the metabolic syndrome and its relation to all-cause and cardiovascular mortality in nondiabetic European men and women. Arch Intern Med 2004;164:1066-76.

8. de Simone G, Devereux RB, Chinali M, Best LG, Lee ET, Galloway JM, Resnick HE, Strong Heart Study Investigators. Prognostic impact of metabolic syndrome by different definitions in a population with high prevalence of obesity and diabetes: The strong heart study. Diabetes Care 2007;30:1851-56

9. The International Diabetes Federation: The IDF consensus worldwide definition of metabolic syndrome 2005. Available at: http://www.idf.org/webdata/docs/ IDF_metasyndrome_definition.pdf. Accessed 15 sep, 2012.

10. Stern MP. The insulin resistance syndrome. In: Alberti KGMM, Zimmet P, DeFronzo RA, eds. International Textbook of Diabetes

\section{REFERENCES}

Mellitus. 2nd ed. Chichester: John Wiley, 1997: pp 255-83.

11. Haffner SM, Valdez RA, Hazuda HP, Mitchell BD, Morales PA, Stern MP. Prospective analysis of the insulin resistance syndrome (Syndrome X). Diabetes 1992; 41: 715-22.

12. Balaker B, Charles MA, Drivsholm T. European group for study of insulin resistance: frequency of the WHO metabolic syndrome in European Cohorts, and an alternative definition of an insulin resistance syndrome. Diabetes Metabolism 2002; 28: 364- 376.

13. Simmon SD, Thompson CF. Prevalence of metabolic syndrome among adult New Zealanders of Polynesian and Europian descent. Diabetes Care 2004;27:3002-3004.

14. Cameron Aj, Shaw JE, Zimmet PZ. The metabolic syndrome: prevalence in worldwide population. Endocrinol Metab clin North Am 2004;33:351-375.

15. Ford ES, Giles WH. A comparison of prevalence of metabolic syndrome using two proposed definition. Diabetes Care 2003;26:575-581.

16. Bonora E, Kiechl S, Willeit J. Carotid atherosclerotic and Coronary heart disease in the metabolic syndrome: proposed data from Bruneck study. Diabetes Care 2003;26:1251-1257.

17. Hanne- Parikka P, Eriksson JG, LindstromJ. Prevalence of the metabolic syndrome and its components: Findings from a Finnish general population sample and the diabetes Prevention Study cohort. Diabetes Care 2004; 27:2135-2140.

18. Pelimpio F, Martinez-Brocca A, Leal-Cerro A. Variability in the presence of the metabolic syndrome in type 2 diabetic patients attending a diabetic clinic: influences of the age and gender. Diab res Clin Pract 2004;65:135-142.

19. Gimeno Orna-JA, Lou Arnal LM, Molineo Herguedas E, Boned Julian B, Portilla Cerdoba DP. Metabolic syndrome as a cardiovascular risk factor in patients with type 2 diabetes. Rev Esp Cardiol 2004; 57:507-513.(in Spanish)

20. Bhattarai S, Kohli SC, Sapkota S. Prevalence of metabolic syndrome in type 2 diabetes mellitus patients using NCEP/ATP III and IDF criteria in Nepal. Nepal Journal of Medical Sciences 2012;1 (2):79-83.
21. Ahmed N, Ahmad T, Hussain SJ, Javed M. Frequency of metabolic syndrome in patients with type-2 diabetes. J Ayub Med Coll Abbottabad 2010;22(1):139-142.

22. Surana SP, Shah Gala DB, Susheja S, Hoskote SS, Gill N. Prevalence of Metabolic Syndrome in an urban Indian diabetic population using the NCEP ATP III guidelines.JAPI 2008;56:865-868.

23. MoonMK, Jung HS, Kim KW, Cho MY, Park YJ, et al. The Prevalence of Metabolic Syndrome and Its Relation with Chronic Diabetic Complications in the Korean Type 2 Diabetic Patients. Korean J Lipidol 2003;13:382-91.

24. Kalish GM, Barrett-Connor E, Laughlin GA. Association of endogenous sex hormones and insulin resistance among postmenopausal women: Results from the Postmenopausal Estrogen/Intervention trial. J Clin Endocrinal Metab. 2003;88:164652.

25. Sarrafzadegan N, Kelishadi R, Baghaei A. Metabolic syndrome: An emerging public health problem in Iranian Women: Isfahan Healthy Heart Program. Int J Cardiol 2008;131:90-6.

26. Rizwan K, Cate B . Appropriate diet and life style intervention can successful treatment of MS in female 2008;57:1502-1508.

27. Thanaa MJ, Tareq HT, Mouneem AS. Metabolic syndrome among Type 2 Diabetic Patients in Babel Goverenate. Medical Journal of Babylon; 7(4): 344-351

28. Imam SK, Shahid SK, Hassan A, Alvi Z. Frequency of the metabolic syndrome in type 2 diabetic subjects attending the diabetes clinic of a tertiary care hospital. J Pak Med Assoc 2007;57:239-42.

29. Bruno G, Merletti F, Biggeri A, Bargero G, Ferrero S, Runzo C, Prina Cerai S, Pagano G, CavalloPerin P, Casale Monferrato Study. Metabolic syndrome as a predictor of all-cause and cardiovascular mortality in type 2 diabetes: The Casale Monferrato study. Diabetes Care 2004;27:2689-94.

30. Foucan L, Deloumeaux J, Donnet JP, Bangou J, Larifla L, Messerchmitt C, Salmi LR, Kangambega P. Metabolic syndrome components in Indian migrants with type 2 diabetes. A matched comparative study. Diabetes Metab 2006;32:337-42. 